\title{
KONTEKSTUALISASI PEMIKIRAN AL-FARABI MENUJU INDONESIA YANG BAHAGIA DAN NEGARA IDEAL
}

\author{
Syamsiyani \\ Universitas Islam Negeri Sunan Kalijaga Yogyakarta \\ Email: nisfiaprilyani96@gmail.com
}

\begin{abstract}
Abstrak: Kecamuk politik yang tengah dipertontonkan di Indonesia akhir-akhir ini semakin menunjukkan buruknya moralitas masyarakat dan peradaban bangsa. Perseteruan politik mulai sejak dahulu memang selalu memicu kontroversi antara baik dan buruk. Al-Farabi mengajak dengan politik bisa mencapai eksistensi ketentraman dan kebahagiaan salah satunya dengan negara yang ideal atau al-Madinah al-Fädilah. Disinilah tujuan menghadirkan sosok filsuf Islam, alFārabi sebagai okoh yang sangat masybur yang terkenal dengan pemikirannya ‘ara Abl al-Mädinah. Tujuan dari tulisan ini untuk mengkontekstualisasikan pemikiran al-Farabi tentang konsep politiknya mencapai kebahagian ummat dan negara yang maju. Metode yang digunakan dalam penelitian ini adalah deskriptif dengan pendekatan kualitatif library research. Pendekatan deskriptif adalah metode penelitian yang bertujuan untuk mengembangkan sebuah teori dari pemikiran atau tokoh. Tujuanya, untuk mengungkapkan realitas pemikiran al-Farabi sesuai dengan kenyataan yang ada di lapangan, dari pemikiran politik al-Farabi diharapkan bisa menciptakan negara Indonesia maju, negara yang bahagia dan ideal, utamanya untuk kehidupan masyarakat secara universal.
\end{abstract}

Kata kunci: Politik Indonesia, Al-Farabi, Kebahagiaan

Title: Contextualization Of Thoughts Al-Farabi Towards A Happy Indonesia and An Ideal Country

Abstract. The political upheaval that has been on display in Indonesia lately is increasingly showing the poor morality of society and the nation's civilization. Political feuds have always started to trigger controversies between good and bad. Al-Farabi invites politics to achieve the existence of peace and happiness, one of which is the ideal state or al-Madinah al-Fādilah. This is where the goal of presenting the figure of the Islamic philosopher, alFärabi as a very famous figure who is famous for his thought 'ara Ahl al-Mādinah. The purpose of this paper is to contextualize al-Färabi's thoughts about his political concept reaching the happiness of the developed community and nation. The method used in this research is descriptive qualitative library research approach. Descriptive approach is a research method that aims to develop a theory of thought or figure. The aim is to reveal the reality of al-Färabi's thinking in accordance with the reality in the field, from al-Farabi's political thinking is expected to create an advanced Indonesian state, a happy and ideal country, especially for universal community life.

Keywords: Indonesian Politics, Al-Farabi, Happiness 


\section{PENDAHULUAN}

Pada dasarnya, manusia diciptakan sebagai makhluk sosial yang saling membutuhkan kepada orang lain. Senada dengan pendapat Filsuf Yunani, Plato dan Aristoteles yang menegaskan tentang kecenderungan manusia bermasyarakat, meminta pertolongan orang lain dan juga membantu orang lain. ${ }^{1}$ Tujuan setiap manusia pasti sama tidak lain untuk hidup bahagia dengan merasakan ketenangan, ketentraman, tanpa adanya kerusuhan atau huru-hara politik, baik antar personal ataupun sosial. Untuk mencapai sebuah kebahagian dalam hidup bermasyarakat maka harus bernegara dan menciptakan simbiolisme utuh antara masyarakat dan suatu pemimpin negara.

Berbicara tentang politik Islam, al-Farabi adalah tokohnya, ia dianggap sebagai salah satu tokoh termasyhur guru kedua (al-mu'allim al-stani), yang tidak akan pernah terlupakan sepanjang sejarah dengan karyanya 'ara abl al-Mädinah al-Fädilah. ${ }^{2}$ Buku ini dilatar belakangi oleh kondisi hidup al-Farabi pada masanya yang terjadi beberapa konflik pemerintahan dan negara, di antaranya perebuatan kekuasaan dinasti Abbasiyah dengan Negara Turki dan Persia. Secara fungsional, negara merupakan institusi dengan tujuan mengakomodir kepentingan individu dalam rangka mewujudkan kebahagiaan hidup bersosial sebagai satu puncak yang diimpikan oleh al-Farabi. ${ }^{3}$

Persoalan tersebut tidak kunjung usai hingga banyak tumpah darah yang berserekan karena persoalan kekayaan, kekuasaan, popularitas, dan lainnya. Dengan ide cemerlangnya alFarabi merasa penting untuk menulis sebuah persoalan dan berbagai solusinya untuk melahirkan negara yang masyaraktnya hidup bahagia. Oleh karenanya, dalam karya ini alFarabi berusaha mengharmonikan antara agama dan filsafat ${ }^{4}$, jadi keduanya tidak ada pertentangan sehingga bisa disatukan sebagai saudara yang rukun dan bersama-sama melahirkan sebuah kebahagian. Pemikiran politik al-Farabi sangat penting dibahas utamanya dalam implikasi saat ini sebagai upaya penyelesaian kemelut masyarakat untuk bisa hidup bahagia dalam bernegara. Konsep kepemimpinan al-Farabi juga mencontoh dari beberapa kepemimpinan Rasulullah untuk umat Islam.

Polemik tentang politik tidak akan pernah usai sepanjang sejarah karena sebuah Negara atau kehidupan tanpa politik seperti rempah-rempah tanpa garam, terasa habar dan tidak enak untuk dimakan. Dunia politik sejatinya menjadi sebuah kebaikan tersendiri di tangan orang-orang yang bertanggungjawab. Berbeda halnya jika diberikan pada pemimpin arogan, dan terlalu melik pada kekuasaan. Hemat penulis, apapun alasan dan proses yang dilakukan,

${ }^{1}$ Moh. Asy'ari Mutthar, The Ideal State: Perspektif Al-Farabi Tentang Konsep Negara Ideal (Yogyakarta: IRCiSoD, 2018), 119-120.

${ }^{2}$ Abdul Wahid Wafa, Al-Madînah Al-Fâdlilah Li Al-Fârâbî, 2nd ed. (Kairo: Alam kutub, 1973), 78. 1 (2019): 64.

${ }^{3}$ Abdullah Said, "Filsafat Politik Al-Farabi," Indonesian Journal of Islamic Theology and Philosophy 1, no.

${ }^{4}$ Ibid., 65. 
Negara tetap membutuhkan pada politik yang baik, pada Pemimpin yang baik, dan mengerjakan segala kewajibannya dengan baik. Kebaikan tersebut tidak lain sebagai penghambaan manusia kepada Tuhannya sebagai fitrahnya untuk khalifah di Muka Bumi. Pasalnya, masyarakat terdiri dari beberapa individu yang saling membutuhkan terhadap orang lain. Al-Farabi menyatakan bahwa manusia secara natural tidak akan pernah bisa memenuhi segala kebutuhan pokoknya dengan seorang diri tanpa bantuan orang lain. Dengan demikian, individual dalam dunia al-Farabi tidaklah berlaku. Ada hal penting yang tetap membutuhkan kesatuan dalam bermasyarakat.

\section{METODE PENELITIAN}

Dalam penelitian ini, metode yang digunakan adalah penelitian deskriptif dengan pendekatan kualitatif. Tujuanya, untuk mengungkapkan realitas pemikiran dengan sebuah kenyataan yang ada di lapangan dengan pendekatan library research. Menurut Furchan penelitian deskriptif adalah metode penelitian yang bertujuan untuk mengembangkan sebuah teori dari pemikir atau tokoh. Penelitian ini memaparkan pemikiran al-Farabi dalam bidang politik. ${ }^{5}$ Referensi primer dalam penelitian ini adalah buku al-Farabi "ara abl al-Madinah alFadilab" dimana al-Farabi ingin menggiring politik sebagai tangga untuk mencapai kebahagiaan dengan cara merumuskan visi-misi bersama yang dilakukan oleh pemimpin dan masyarakat. Realitas saat ini menjadi fenomena yang menarik saat pemikiran al-Farabi melebur ikut meramaikan konstelasi politik yang semakin carut marut. Selain itu refensi juga diambil dari buku-buku filsafat, jurnal, dan dikumentasi yang berkaitan dengan pokok pemikiran politik al-Farabi. Sebagaimana Bernad W. Andrews (2016) mengatakan bahwa, metode penelitian kualitatif harus mengeksplorasi lebih dalam lagi dari sudut pandang filosofis yang bisa dibawa ke dalam pergolakan akademik secara serius. ${ }^{6}$ Epistemologi yang dibangun disini diposisikan sebagai sarana instrumentalisme untuk menjalskan pemikiran alFarabi secara mendalam. Melalui beberapa problem politik yang dipaparkan dimuka akan mengungkapkan sesuatu yang unik dan khas yang bisa dipelajari dari suatu penelitian yang lain untuk menunjukkan perbedaan pandangan filosofis dari artikel ini yang fokus membicarakan pemikiran politik al-Farabi ke tengah gelangganan politik mutakakhir.

\section{TEMUAN DAN PEMBAHASAN \\ Perjalanan Singkat Hidup al-Fārabi}

Selain pemikirannya yang ditulis di perbagai karya, problematika yang sangat sulit untuk ditemukan adalah informasi lengkap terkait dengan biografi al-Farabi. Akan tetapi penulis

\footnotetext{
5 Arief Furchan, "Pengantar Penelitian Dalam Pendidikan," Yogyakarta: Pustaka Pelajar (2004).

${ }^{6}$ BERNARD W ANDREWS, "PARTNERSHIP ISSUES,” Counterpoints 502 (2016): 15-21.
} 
berusaha menguraikan sesuai data yang didapatkan dari berbagai buku karya al-Fārabi. ${ }^{7}$ Nama lengkapnya adalah Abu Nashr Muhammad ibn Muhammad ibn Tarkhan ibn Al-Uzalagh alFarabi dan dipanggil dengan sebutan al-Fārabi. Dilahirkan di Wasij-Distrik Farab (yang dikenal dengan Utrar) di Transoxiana. ${ }^{8}$ Nama al-Fārabi diambil dari nama kotanya yaitu Farab, tempat Ia dilahirkan pada tahun 257 H. bertepatan 870 M., Ayahnya seorang jenderal berkebangsaan persia dan ibunya berkebangsaan Turki. ${ }^{9}$ Al-Farabi meninggal di Damaskus pada tahun 339 H./950 M. Dalam usia 80 tahun. ${ }^{10}$

Al-Fārabi hidup pada masa Dinasti Abbasiyah dengan kepemerintahan al-Mu tamid. Kehidupan pada masa itu penuh dengan gejolak pemberontakan baik secara agama, suku, budaya, ras, dan lainnya. Stabilitas yang terjadi pada masa kehidupan al-Fārabi menunjukan bahwa Ia hidup dengan berbagai kemelut politik yang berada disekelilingnya. Dengan kejadian tersebut membuat al-Fārabi melahirkan sebuah ide dengan konsep politik dalam negara. ${ }^{11}$ Selain itu, pemikiran filsafat al-Fārabi juga dipengaruhi oleh Filsuf Yunani seperti Plato, Aristoteles. Salah satu pengaruh Plato bahwa negara yang ideal harus berdasarkan sebuah keadilan yang dipimpin dengan seorang Filsuf. Dengan latar belakang kehidupan politik dan kondisi kehidupan pada saat itu, maka al-Fārabi melahirkan suatu konsep politik tentang negara utama atau negara ideal yang tertulis dalam karyanya 'Ara Abl al-Madinal alFädhilah. Aristoteles juga berpendapat bahwa negara yang ideal harus memiliki pemimpin yang adil. Keadilan bisa dicapai apabila ada kerjasama serta tujuan yang sama antara negara dan masyarakat yang tingal di dalamnya. Sedangkan menurut Plato, negara seperti tubuh yang tidak bisa dipisahkan antara satu organ dengan organ yang lainnya. Apabila salah satu organ rusak maka rusak pula suatu negara. Plato mengibaratkan tubuh layaknya sebuah ideologi, masyarakat, dan negara.

\section{Latar Belakang Pemikiran Politik al-Fārabi}

Setiap pemikiran pasti dilatar belakangi oleh sebuah historis pemikiran para gurugurunya. Begitupun dengan sosok yang disebut sebagai al-mu allim ats-tsani (guru kedua) setelah Aristoteles yang menguak pemikirannya tentang konsep negera ideal atau negera yang utama. Kondisi politik pada saat itu sangat kacau-genting dalam kepemimpinan al-Mu tamid pada masa Dinasti Abbasiyah. Pertumpahan darah seperti serapah yang berlalu lalang setiap hari. Pemberontakan, kekerasan, peperangan bukanlah hal yang tabu pada masa itu. Dari pelbagai golongan baik suku dan ras terus terjadi di kalangan Abbasiyah. Banyak yang

\footnotetext{
${ }^{7}$ Zuhri, Mantiq Dalam Diskursus Filsafat Islam (Yogyakarta: FA PRES, 2019), 46-47.

${ }^{8}$ Abu Nasr Muhammad Al-Farabi, Hayatuhu, Atsaaruhu, Falsafatuhu (Beirut: Daar al-Kutub al-Ilmiyah,

${ }^{9}$ Sirajuddin Zar, Filsafat Islam: Filosof Dan Filsafatnya (Jakarta: Raja Grafindo Persada, 2012), 65.

${ }^{10}$ Mutthar, The Ideal State: Perspektif Al-Farabi Tentang Konsep Negara Ideal, 124.

${ }^{11}$ Yamami, Antara Al-Farabi Dan Khomaini Filsafat Politik Islam, (Bandung: Mizan Media Utama, 2002),
} 1990), 7-8. $52-53$. 
menjadi perantara motif terjadinya kerusuhan dan pemberontakan tersebut, diantaranya motif keagamaan, kesukuan, perebutan kekayaan, dan sebagainya. ${ }^{12}$ Motif tersebut terjadi karena semangat orang-orang Turki dan Persia untuk merebut kekuasaan Abbasiyah. Baginya kekuasaan tersebut merupakah hak warisan dari nenek moyang mereka untuk tetap dijaga dan dikuasai oleh negaranya sendiri.

Kondisi tersebut semakin kacau dengan datangnya kelompok Syi ah yang memberontak, bahwa hanya keturunan Ali bin Abi Thalib yang berhak memerintah negara Islam daripada Dinasti Abbasiyah. Pemberontakan tersebut semakin berlanjut dipelbagai daerah, termasuk kelompok Negro yang berasal dari Afrika Timur yang biasa dikenal dengan kaum Zenj. Mereka terus melakukan serangan tentara khalifah sehingga bisa menguasai daerah sekitar Bashrah. Kondisi tersebut semakin parah dan terus berlanjut akhirnya Dinasti Abbasiyah hancur pada tahun 656 H/1258 M. Meskipun dengan kehancurannya yang sangat tragis, Abbasiyah pernah mencapai masa keemasan sekitar satu abad yang dipimpin oleh khalifah pertama, Abu Abbas Abdullah al-Saffah bin Muhammad yang dilanjutkan oleh khalifah selanjutnya, dan sampai pada khalifah kesembilan yaitu khalifah al-Mu 'tashim. ${ }^{13}$ Kondisi politik tersebutlah menjadi cikal bakal pola pemikiran Filsafat politik al-Farabi dalam kitab ‘ara Abl al-Madinah al-Fädhilah.

Selain kondisi politik pada masa itu, pemikiran politik al-Fārabi juga dipengaruhi oleh pemikiran politik Plato yang mengemukakan bahwa negara terbentuk dari perbedaan jiwa manusia dan masyarakat yang sempurna. Pemikiran Plato kemudian dilanjutkan oleh Aristoteles yang mengatakan bahwa, negara adalah gabungan sebuah keluarga yang menjadi kelompok besar. ${ }^{14}$ Jadi, kebahagian negara akan tercapai jika terciptanya kebahagian individu. Sebaliknya, jika manusia ingin bahagia maka harus bernegara.

\section{Tentang Politik}

Istilah "politik" dalam bahasa Indonesia terambil dari kata bahasa Inggris: politic, yang secara harfiah bermakna (a) acting or juding wisely; prudent (b) well judged; prudent atau sikap bijaksana atau hati-hati dalam bersikap, dan melakukan kebijaksanaan atau tindakan bijak. Kata tersebut juga bermakna The art of government atau tata pemerintahan/seni pemerintahan. ${ }^{15}$ Plato termasuk yang mengkritik demokrasi, menurutnya sistem kepemimpinan demokrasi sangat tidak becus karena kepemimpinan didapatkan dari hasil suatu rakyaktnya. Melaui kritiknya tersebut Plato melahirkan konsep aristokratis dan otokratis tentang idealnya masyarakat yang sempurna: masyarakat yang dipimpin filsuf. ${ }^{16}$ Sedangkan menurut politik al-

\footnotetext{
${ }^{12}$ Mutthar, The Ideal State: Perspektif Al-Farabi Tentang Konsep Negara Ideal, 110.

${ }^{13}$ Ibid., 110-111.

${ }^{14}$ Ibid., 121.

15 Burhanuddin Yusuf, "Politik Dalam Islam: Makna, Tujuan Dan Falsafah (Kajian Atas Konsep Era Klasik)," Aqidah-Ta: Jurnal Ilmu Aqidah 4, no. 1 (2018): 114-130.

${ }^{16}$ Yamami, Antara Al-Farabi Dan Khomaini Filsafat Politik Islam, 77.
} 
Fārabi demokratis sebuah kota yang setiap penduduknya diberikan kebebasan penuh untuk melakukan apapun yang dikehendakinya. Sebab itu, setiap warga negara harus memiliki ide untuk memperjuangkan cita-cita yang telah dirancang bersama. Tujuan dari sebuah negara yang ideal tidak lain adalah kebahagian (bappiness). ${ }^{17}$ al-Fārabi merekonsiliasi kedua pemikiran tersebut tentang sebuah negara ideal yang tertuang dalam kitab ‘ara Ahl al-Madinah al-Faādilah secara substansial yang diilhami dari buku republik karya Plato. Jika Plato menekankan pemimpin lebih kepada jasmani, maka menurut al-Fārabi lebih kepada spiritual. Jadi negara ideal ketika tujuan masyarakat bisa menyeimbangkan antara kekuatan jasmani dan akhirat atau spiritual. ${ }^{18}$

Menurut Plato kerjasama yang baik antar individu akan memenuhi kepentingan untuk dirinya sendiri dan juga orang lain yang hidup dalam kesatuan masyarakat. Masyarakat adalah negara itu sendiri. Jadi masyarakat yang berkualitas dengan gagasan-gagasan cemerlangnya akan membentuk suatu negara yang melahirkan sistem kebahagian dan kesejahteraan. Sebab itulah, al-Fārabi menjadikan seorang Filsuf yang memiliki sifat seperti Nabi sebagai kriteria untuk menjadi pemimpin. ${ }^{19}$ Sebagaimana dalam buku The Ideal State perspektif al-Fārabi tentang negara ideal, masyarakat terdiri dari beberapa individu yang saling membutuhkan terhadap orang lain. al-Fārabi menyatakan bahwa manusia secara natural tidak akan pernah bisa memenuhi segala kebutuhan pokoknya dengan seorang diri tanpa bantuan orang lain. Oleh karenanya, setiap individu membutuhkan pada individu yang lain sehingga terjalin sebuah persaudaraan dan saling pengertian antar sesama. ${ }^{20}$ Dalam kitab al-Siaysah alMädaniyah, masyarakat terbagi menjadi tiga bagian: Pertama, komunitas besar adalah komunitas yang bertempat di al-ma 'muroh (komunitas masyarakat dunia). Kedua, komunitas sedang adalah suatu masyarakat yang bertempat tinggal di sebagian dunia. Ketiga, komunitas kecil adalah suatu masyarakat yang bertempat tinggal di bagian-bagian dari belahan suatu wilayah. ${ }^{21}$ Sedangkan yang dimaksud dari negara utama atau ideal adalah komunitas sempurna yang memiliki cita-cita sama dan memiliki banyak perubahan untuk mencapai sebuah kebahagian.

\section{Tentang Negara}

Setiap Negara pasti memiliki tujuan (ends of the state), untuk mencapai sebuah visi bersama. Al-Fārabi menegaskan bahwa setiap warga negara harus mempunyai ide yang harus diperjuangkan oleh setiap individu atau masyarakat dan berjanji untuk menomorsatukan cita-

${ }^{17}$ Mahmuda, "KONSEP NEGARA IDEAL/UTAMA (AL-MAḌīNAH AL-FĀḌILAH) MENURUT ALFARABI," 86.

${ }^{18}$ Zar, Filsafat Islam: Filosof Dan Filsafatnya, 85.

${ }^{19}$ Mutthar, The Ideal State: Perspektif Al-Farabi Tentang Konsep Negara Ideal, 120.

${ }^{20}$ Al-Farabi, Hayatuhu, Atsaaruhu, Falsafatuhu, 176.

${ }^{21}$ Ibid., $180-181$. 
cita negara dan menghilangkan cita-cita untuk kepentingan dirinya sendiri. ${ }^{22}$ Al-Fārabi membagi negara pada lima macam yakni:23 Pertama, Al-Madinah al-Fadilah; masyarakat yang bertujuan untuk kebahagian. Kebahagian tersebut bisa dicapai jika memiliki masyarakat yang mempunyai visi misi sama untuk sebuah negara tanpa mementingkan kepentingan individualismenya. Kedua, al-Madinah al-Jahiliah; negata tidak mempunyai tujuan untuk sebuah kebahagian, negara ini dibagi menjadi enam: (a) al-Madinah al-Dharuriyyah, (b) al-Madinah alBaddalah,(c) al-Madinah al-Khissah wal al-Siqut, (d) al-Madinah al-Karimah, (e) al-Madinah alTaghallub, (f) al-Madinah al-Jamaiyyah.

Ketiga, al-Madinah al-Mutabaddilah (negara penyeleweng), sebuah negara yang pandanganpandangan dan perbuatan-perbuatan penduduknya pada mulanya sama dengan pandangan dan perbuatan masyarakat negara utama, akan tetapi seiring bergantinya waktu pandangannya berubah karena direduksi dengan masuknya pandangan lain sehingga menyeleweng dari pandangan semula. Kelima, al-Madinah al-Ḍhallah (negara sesat) penduduknya memiliki pemikiran salah tentang Tuhan dan akal aktif.. Pemimpin mereka adalah seorang penipu dan pembohong. Pemimpin di negara tersebut berpura-pura menerima wahyu, kemudian Ia menipu orang lain dengan ucapan dan tingkah lakunya agar mereka mengikutinya sebagaimana halnya seorang $\mathrm{Nabi}^{24}$

Mengulas pemikiran politik al-Fārabi sebenarnya masih mengandung pelbagai diskursus. Sebagian ada yang berpendapat pemikiran al-Fārabi berasal dari Filsafat Yunani yang terkonstruksi oleh pemikiran Plato dan Aristoteles, ada sebagian yang berpedapat pemikiran al-Fārabi murni dari pemikirannya sendiri. Terlepas dari semua itu, baik kontruksi dari pemikiran barat ataupun pemikiran Timur, pemikiran politik al-Fārabi dapat disimpulkan sebagai pemikiran politik Islam. Dalam hal ini menggunakan parameter persoalan relasi antara agama dan negara. ${ }^{25}$ Ada tiga paradigma munculnya perdebatan relasi antara agama dan negara: Pertama, Paradigma Integralistik adalah sebuah paradigma yang berasumsi bahwa, agama dan negara menyatu. Pemimpin sebagai pemegang kekuasaan agama dan politik. Sedangkan pemerintahan yang ada hanyalah atas kehendak Tuhan. Paradigma ini yang dianut oleh kelompok Syiah, akan tetapi istilah kepemimpinan dalam kelompok Syiah disebut sebagai imamah. Menurut kelompok ini menganggap bahwa Islam merupakan agama yang sempurna. Maka umat Islam tidak perlu mengimport sistem politik Barat yang sangat kental sekularisme. Paradigma ini dianggap sama dengan pemerintahan Rasulullah yaitu negara teokrasi, yang dipahami bahwa segala kekuasaan atas kehendak Sang Khalik. ${ }^{26}$ Kedua,

\footnotetext{
${ }^{22}$ Said, "Filsafat Politik Al-Farabi," 66.

${ }^{23}$ Abu Nasr Muhammad Al-Farabi, Ara Al-Ahl Al-Madinah Al-Fadilah (Mesir: Hindawi, 2012), 79-81.

${ }^{24}$ Imam Sukardi, "Negara Dan Kepemimpinan Dalam Pemikiran Alfarabi," Al-A'raf: Jurnal Pemikiran Islam dan Filsafat 14, no. 2 (2017): 289-290.

${ }^{25}$ Mutthar, The Ideal State: Perspektif Al-Farabi Tentang Konsep Negara Ideal, 124-125.

${ }^{26}$ Ibid., 126-128.
} 
Paradigma simbiotik. Paradigma ini antara agama dan negara memiliki hubungan artinya hubungan timbal balik yang saling membutuhkan atau disebut juga sebagai simbiosis mutualisme dalam ilmu pengetahuan alam. Agama membutuhkan negara, karena dengan negara agama bisa berkembang. Sebaliknya, negera juga membutuhkan agama dalam perkembangan moral, etik, dan spiritual masyarakat. ${ }^{27}$ Menurut paradigma ini boleh-boleh saja mengimport sistem Barat selama tidak bertentangan dengan ajaran Islam. Paradigma ini cenderung moderat antara teori pertama dan teori ketiga. Ketiga, Paradigma sekularistik merupakan paradigma yang menolak paradigma pertama dan kedua. Sebagai gantinya paradigma ini mengajukan perceraian antara negara dan agama. Negara dipahami sebagai suatu tempat kelompok masyarakat tertentu dan aturan yang ada dalam negara tersebut tidak ada kaitannya dengan agama yang mereka anut. Negara ini tidak boleh mengurusi persoalan rakyatnya. Agama tidak bisa mengintervensi terhadap kebijakaan negara. Negara hanya sebagai hubungan horizontal antara manusia dengan dunia, sedangakan agama sebagai hubungan vertikal antara manusia dengan Tuhan. Jadi, menurut paradigma sekularistik sangat tidak bisa dibedakan antara dua dimensi yang berbeda. ${ }^{28}$

Dari ketiga paradigma tersebut, al-Fārabi memposisikan agama dalam negara sebagai fungsi penjagaan etika, moralitas dan spiritual, karena menurutnya syarat seorang pemimpin yang ideal ialah seorang Nabi atau Filsuf. Selain itu, negara yang baik apabila negara tersebut dan masyarakatnya saling bekerjasama layaknya anggota tubuh yang memilki fungsi masingmasing. Jika salah satu anggota tubuh tersebut tidak berfungsi, maka tidak berfungsi pula suatu sistem negara di dalamnya sehingga tidak tercipta suatu kebahagian yang diimpikan oleh masyarakat.

\section{Konsep Politik al-Fārabi Menuju Indonesia Bahagia}

Hakikat dari sebuah kebahagian menurut al-Fārabi adalah kebaikan yang diinginkan untuk kebaikan itu sendiri. ${ }^{29}$ Cara memperolehnya dengan empat keutamaan: keutamaan teoritis, berpikir, akhlak, dan berkreasi. Jika mendapatkan apa yang diinginkan mata bisa dikatakan bahagia, kata Bettina Cheng, salah satu Penulis Teknis. ${ }^{30}$ Polemik yang menjadi objek saat ini adalah tentang kebahagian itu sendiri. Tujuan dari kehidupan tidak lain hanya untuk mendapatkan kebahagian. ${ }^{31}$ Ada pula sebagian yang mengartikan bahwa kebahagian berarti jika mendapatkan materi, jabatan, wanita dan yang lainnya, ada juga yang merasa sudah bahagia dengan segala yang dimiliki. ${ }^{32}$

\footnotetext{
${ }^{27}$ Ibid., 128.

${ }^{28}$ Ibid., 129-130.

${ }^{29}$ Abu Nashr Al-Farabi, Risalah Tanbih 'Ala Sabil as-Sa'Adah (Amman: Universitas Yordania, 1987), 15.

${ }^{30}$ Ann Harleman, "HAPPINESS," The Virginia Quarterly Review 69, no. 2 (1993): 209-327.

${ }^{31}$ Anthony Kenny, "Happiness," Proceedings of the Aristotelian Society 66 (1966): 93-102.

${ }^{32}$ Ibid.
} 
Dari sisi lain, kebahagiaan dan kesenangan merupakan hal yang solid, artinya keduanya merupakan kekuatan utuh yang tidak bisa dipisahkan. Meraihnya dengan cara menghindari sifat hedonisme dan hal-hal lain yang bersifat induvidual. Proses ini yang kemudian diolah guna masyarakat meninggalkan hal-hal negatif yang tidak diperbolehkan. ${ }^{33}$ Memang sebagian berpendapat bahwa kebahagian dan kesenangan memiliki perbedaan yang sangat tipis, oleh karenanya tidak boleh ditarik dalam konklusi yang terlalu ekstrim. Menurut World Happiness Report yang diterbitkan oleh (United Nation Sustainable Development Solutions Network) Berdasarkan data dari Badan Pusat Statistik, indeks kebahagiaan Indonesia mengalami peningkatan dari tahun 2014 dan 2017. Pada tahun 2014 sebesar 68,28 dan meningkat menjadi 70,69 pada tahun 2017. Indeks Kebahagiaan Indonesia ini disusun oleh tiga dimensi yaitu Kepuasan Hidup, Perasaan dan Makna Hidup. Meskipun angka korupsi di Indonesia naik akan tetapi angka kebahagiaan semakin meningkat. ${ }^{34}$ Itu artinya, Indonesia belum bisa dikatakan sebagai negara yang ideal.

Banyak masyarakat Indonesia yang masih saling sikut, saling fitnah, saling menyebarkan kebencian antar sesama, banyak kelompok antar kelompok yang lain berbeda pendapat, dan menunjukkan pendapat tentang negara yang berbeda-beda. Itu yang disoroti oleh al-Fārabi untuk menyatukan visi-misi yang dibangun bersama menuju kebahagian bersama. ${ }^{35}$ Kebahagiaan itu adalah kebaikan yang diinginkan untuk kebaikan itu sendiri. ${ }^{36}$ Dalam kitabnya Tahsil Ala Säbil al-Sa ādab ${ }^{37}$ masyarakat akan mendapatkan kebahagian ketika menyadari dalam dirinya ada empat keutamaan: baik keutamaan teoritis, berpikir, akhlak, dan berkreasi.

Untuk mencapai Indonesia sebagai negara yang ideal maka paling tidak harus melakukan pencapaian-pencapaian kebahagiaan yang dikatakan oleh al-Fārabi. Kebahagiaan itu kata al-Fārabi ada dua bagian: pertama, kebahagain yang terkait dengan kesusilaan yaitu; siapapun bisa mencapai kebahagian ini dengan catatan telah melaksanakan apa yang diperintahkan pemimpin dan tidak melakukan hal-hal yang dilarang. Kedua, kebahagian yang terkait dengan aqliah. Kebahagian ini hanya orang-orang tertentu yang bisa mencapainya sesuai dengan kadar kemampuan akal yang dimiliki untuk memikirkan segala hal sampai pada dasarnya. ${ }^{38}$ Sedangkan untuk bahagia menurut Plato pemimpin harus seorang Filsuf dan Filsuf bisa menjadi pemimpin, maka jika pada konteks Indonesia seorang pemimpin adalah sosok yang bijaksana, sosok yang cerdas dalam mengambil kebijakan dan membuat programprogam untuk masa depan bangsa. Menurut al-Fārabi, selain pemimpin harus seorang Filsuf

\footnotetext{
${ }^{33}$ Henry Sturt, “Happines,” International Journal of Etika 13, no. 2 (1903): 207-221.

34 "How Happy Are Indonesians, Really?," The Jakarta Post, 2020, https://www.thejakartapost.com/news/2014/04/17/how-happy-are-indonesians-really.html .

${ }^{35}$ Al-Farabi, Risalah Tanbih 'Ala Sabil as-Sa'Adah, 15.

${ }^{36}$ Ibid.

${ }^{37}$ Al-Farabi, Tahsil Al-Sa'ādah (Da’irah al-'Usmaniah: Hyderabad, 1345).

38 Mustain Mustain, "Etika Dan Ajaran Moral Filsafat Islam: Pemikiran Para Filosof Muslim Tentang Kebahagiaan," Ulumuna 17, no. 1 (2013): 191-212.
} 
artinya yang bijak, juga harus memiliki kearifan baik secara pikiran dan rasio ataupun berdasarkan wahyu. Seorang kepala negara haruslah bersifat arif dan bijaksana dalam menentukan dan mengelola suatu negara. ${ }^{39}$

Negara mencapai negara Indonesia yang ideal harus memiliki tiga syarat keunggulan, unggul dalam ilmu pengetahuan, unggul dalam ideologi, dan unggul dalam agama. Dengan dipimpin oleh seorang kepala negara yang ideal, yakni seorang Filsuf atau yang bijak atau seseorang yang seperti Nabi. Dari situlah muncul filsafat kenabian yang dikatakan oleh alFārabi lahir karena disebabkan adanya pengingkaran terhadap eksistensi kenabian secara filosofis oleh Ahmad bin Ishaq al-Ruwandi, salah satu tokoh dari kebangsaan Yahudi yang melahirkan beberapa karya tulis tentang pengingkaran kenabian yang utamanya tertuju pada Nabi Muhammad Saw. ${ }^{40}$

Maka syarakat sebagai pemimpin Indonesia jika diformulasikan dengan konsep alFārabi adalah terdiri dari dua belas: Pertama, Pemimpin atau kepala harus memiliki tubuh yang sehat, semua organ tubuhnya bisa berfungsi dengan baik agar Ia dapat melakukan setiap fungsi atau tugas yang diberikan kepadanya. Kedua, mampu memahami apa yang dikatakan dan memberikan pemahaman yang baik kepada rakyatnya. Ketiga, memiliki kekuatan yang baik dari apa yang dipahami, dilihat, didengar atau dirasakan;. Keempat, memiliki ingatan yang baik terhadap apa yang dipahami, dilihat, didengar atau yang dirasakan. Kelima, fasih dalam mengartikan apapun yang ingin disampaikan. Keenam, Mencintai pembelajaran atau menerima dan menjalani proses, menerima instruksi, tidak terhalang oleh petugas di atasnya. Ketujuh, tidak tamak dalam hal makanan, minuman atau jenis kelamin, membenci permainan dan kesenangan yang ditimbulkan olehnya. Kedelapan, mencintai kebenaran dan ahlinya, serta membenci dusta dan ahlinya. Kesembilan, murah hati dan mencintai kehormatan dan membenci apapun yang dapat memalukan, dia harus murah hati dan pencinta kehormatan, yang membenci secara alami apa pun yang memalukan. Kesepuluh, Tidak tertarik pada uang dan barang-barang dunia. Kesebelas, menjadi pencinta keadilan dan pembenci ketidakadilan; adil dalam berurusan dengan yang tertindas dan cepat menanggapi panggilan untuk ganti rugi. Keduabelas, teguh dalam tekadnya untuk melakukan apa yang menurutnya benar, berani, dan berani. ${ }^{41}$ Kriteria tersebut menjelaskan bahwa, al-Fārabi ingin merekonsiliasi atau mengawinkan konsep negara pemikiran filsafat Yunani dengan Konsep Negara Islam. ${ }^{42}$ Konsep inilah sangat penting untuk diterapkan di Indonesia sebagai negara yang mayoritas masyarakatnya adalah muslim.

${ }^{39}$ Muhammad Iqbal and Amin Husein Nasution, Pemikiran Politik Islam: Dari Masa Klasik Hingga Indonesia Kontemporer (Kencana, 2010), 13.

${ }^{40}$ Mutthar, The Ideal State: Perspektif Al-Farabi Tentang Konsep Negara Ideal, 120.

41 Al-Farabi Majid Fakhry, Founder of Islamic Neoplatonism: His Life Work and Influence (England: Oneworld Publication, 2002), 103-105.

${ }^{42}$ M Wiyono, "Pemikiran Filsafat Al-Farabi," SUBSTANTIA: Jurnal Ilmu-Ilmu Ushuluddin 18, no. 1 (2016): 67-80. 


\section{KESIMPULAN}

Menciptakan negara yang ideal maka akan melahirkan kondisi kehidupan masyarkat yang bahagia. Politik sebagai salah satu jalan menuju kebahagian. Untuk mencapai semua itu, tidak bisa melupakan fungsi individu sebagai makhluk sosial yang saling membutuhkan. Negara dan masyarakat harus bekerjasama untuk menciptakan kerja sama visi-misi untuk menuju kebahagiaan. Sedangkan yang dimaksud dari negara utama atau ideal adalah komunitas sempurna yang memiliki cita-cita sama dan memiliki banyak perubahan untuk mencapai sebuah kebahagiaan. Al-Fārabi membagi negara menjadi lima macam yakni: (a) alMadinah al-Fadilah (b) al-Madinah al-Jabiliah (c) al-Madinah al-Fasiqah (d) al-Madinah alMutabaddilah (e) al-Madinah al-Dhballah. Menurutnya, negara utama sebagai jalan kebahagian memiliki tiga syarat keunggulan, unggul dalam ilmu pengetahuan, unggul dalam ideologi, dan unggul dalam agama. Negara yang ideal dipimpin oleh seorang filsuf atau bijaksana yang memiliki sifat seperti Nabi. Indonesia harus memiliki pemimpin yang bijak sebagaimana ada dua belas syarat yang dikemukakan al-Fārabi. Maka konsep politik al-Fārabi bisa diterapkan pada kepemimpinan Indonesia saat ini dalam artian bukan persoalan sistemnya antara demokrasi, monarki, aristokrasi, atau yang lainnya, melainkan semangat konsep negara idela al-Madinah al-Fadilah sebagai salah satu jalan untuk menciptakan kehidupan yang bahagia dalam suatu negara. Kebahagian tersebut tidak hanya bisa dicapai oleh adanya pemimpin dengan kriteria mendekati nabi atau filsuf, melainkan juga sumbangsih ide dari masyarakat sendiri.

\section{DAFTAR PUSTAKA}

Al-Farabi. Tahsil Al-Sa’ādah. Da’irah al-'Usmaniah: Hyderabad, 1345.

Al-Farabi, Abu Nashr. Risalah Tanbih 'Ala Sabil as-Sa'Adah. Amman: Universitas Yordania, 1987.

Al-Farabi, Abu Nasr Muhammad. Ara Al-Abl Al-Madinah Al-Fadilah. Mesir: Hindawi, 2012. Hayatuhu, Atsaaruhu, Falsafatubu. Beirut: Daar al-Kutub al-Ilmiyah, 1990.

ANDREWS, BERNARD W. "PARTNERSHIP ISSUES.” Counterpoints 502 (2016): 23-30.

Furchan, Arief. "Pengantar Penelitian Dalam Pendidikan.” Yogyakarta: Pustaka Pelajar (2004).

Harleman, Ann. "HAPPINESS." The Virginia Quarterly Review 69, no. 2 (1993): 309-327.

Iqbal, Muhammad, and Amin Husein Nasution. Pemikiran Politik Islam: Dari Masa Klasik Hingga Indonesia Kontemporer. Kencana, 2010.

Kenny, Anthony. "Happiness.” Proceedings of the Aristotelian Society 66 (1966): 93-102.

Mahmuda, Mahmuda. "KONSEP NEGARA IDEAL/UTAMA (AL-MAḌ̄NAH AL- 
FĀḌILAH) MENURUT AL-FARABI.” AL-LUBB: International Journal of Islamic Thought and Muslim Culture (IJITMC), no. 1 (2017): 286-300.

Majid Fakhry, Al-Farabi. Founder of Islamic Neoplatonism : His Life Work and Influence. England: Oneworld Publication, 2002.

Mustain, Mustain. "Etika Dan Ajaran Moral Filsafat Islam: Pemikiran Para Filosof Muslim Tentang Kebahagiaan.” Ulumuna 17, no. 1 (2013): 191-212.

Mutthar, Moh. Asy'ari. The Ideal State: Perspektif Al-Farabi Tentang Konsep Negara Ideal. Yogyakarta: IRCiSoD, 2018.

Said, Abdullah. "Filsafat Politik Al-Farabi." Indonesian Journal of Islamic Theology and Philosophy 1, no. 1 (2019): 63-78.

Sturt, Henry. "Happines." International Journal of Etika 13, no. 2 (1903): 207-221.

Sukardi, Imam. "Negara Dan Kepemimpinan Dalam Pemikiran Alfarabi." Al-A'raf: Jurnal Pemikiran Islam dan Filsafat 14, no. 2 (2017): 283-306.

Wafa, Abdul Wahid. Al-Madînah Al-Fâdlilah Li Al-Fârâbî. 2nd ed. Kairo: Alam kutub, 1973.

Wiyono, M. "Pemikiran Filsafat Al-Farabi." SUBSTANTIA: Jurnal Ilmu-Ilmu Ushuluddin 18, no. 1 (2016): 67-80.

Yamami. Antara Al-Farabi Dan Khomaini Filsafat Politik Islam,. Bandung: Mizan Media Utama, 2002.

Yusuf, Burhanuddin. "Politik Dalam Islam: Makna, Tujuan Dan Falsafah (Kajian Atas Konsep Era Klasik)." Aqidah-Ta: Jurnal Ilmu Aqidah 4, no. 1 (2018): 114-130.

Zar, Sirajuddin. Filsafat Islam: Filosof Dan Filsafatnya. Jakarta: Raja Grafindo Persada, 2012.

Zuhri. Mantiq Dalam Diskursus Filsafat Islam. Yogyakarta: FA PRES, 2019.

"How Happy Are Indonesians, Really?" The Jakarta Post, 2020. https://www.thejakartapost.com/news/2014/04/17/how-happy-are-indonesiansreally.html . 